\title{
Development of Twelve Parameter Prediction Model for Examining the Under-Pipe Corrosion Deposit Condition of Localized Carbon Steel in Acidic Media
}

\author{
OBASEKI, M \\ Department of Mechanical Engineering, Faculty of Engineering, University of Port Harcourt, Port Harcourt, Nigeria \\ Corresponding Author Email:obasekimartins@gmail.com
}

\begin{abstract}
This paper presents an under deposit condition of localized carbon steel in acidic gas solutions by developing and using a twelve parameters condition prediction model. The proposed analytical model was tested against De Waard models, neural network model and experimental result and found to have an accuracy of $82.4 \%$ against $23 \%$, $53.3 \%, 95.6 \%$ of De Waard Lotz and Milliams models and NN mode and was found to give reasonably accurate results. It had root mean square error (RMSE) of 0.024 , mean absolute error (MAE) 0.019 , scattered index (SI) 0.371 and with coefficient of determination $\left(\mathrm{R}^{2}\right)$ of $82.4 \%$ in the validation series. The method is useful for introducing nonlinear conditions prediction in undergraduate/postgraduate engineering with manual computation coupled with lesser error and very simple method in application for better corrosion management than the existing manual traditional models.
\end{abstract}

\section{DOI: $\underline{\text { https://dx.doi.org/10.4314/jasem.v23i6.4 }}$}

Copyright: Copyright $@ 2019$ Obaseki. This is an open access article distributed under the Creative Commons Attribution License (CCL), which permits unrestricted use, distribution, and reproduction in any medium, provided the original work is properly cited.

Dates: Received: 13 May 2019; Revised: 19 June 2019; Accepted 07 June 2019

Keywords: Model, under-deposit, Carbon steel, Corrosion management

Oil, gas and other petroleum products are mostly produced in large expanses situated far from consumption middles. This implies that the oil and gas must be transferred to refineries, and their refined products moved from producing regions to utilization centers. Conversely, pipeline substructure is the primary means of conveying this natural gas and the crude oil. Furthermore, pipelines play important role in modern societies like Nigeria and are crucial in providing needed fuels for sustaining vital functions such as transportation, power generation, cooking and heating supplies (Tawancy et al., 2013). Petrochemical processes companies also use oil and gas to make useful products. Additionally, pipelines are recognized as the safest and most economical mode of petroleum products transportation across far distances and over difficult terrains (Tawancy et al., 2013; Teixeira et al., 2008).

Pipelines as an engineering facility do fail in-service owing to deterioration. This is mostly climaxed by the environmental factors such as; moisture, oxygen, temperature and even intensive property like pressure. However, the latter factors put together on the exposed facility leads to a complex scenario termed corrosion (Ahammed, 1998; Mohitpour et al., 2007). Corrosion is a major problem in pipeline engineering and materials transportation as it may result to high maintenance cost, and in some case huge, financial and economic loses. Oil and gas steel pipeline buried underground deteriorate because of an electrochemical reaction with the environment. Corrosion is the deterioration of material, usually a metal, because of a reaction with its environment and which requires the presence of an anode, a cathode, an electrolyte, and an electronically circuit which important of corrosion is in economic, safety, and conservation of resources (Revie and Uhlig, 2008). In addition, if no proper preventive maintenance is carried out, and there is leakage, it tends to cost the operators huge cost of replacement that lead to production shutdown, loss of fluid, loss of efficiency and high cost of fuel and energy as a result of leakage of corroded pipeline (Mohitpour et al., 2007). Corrosion is a major potential problem in the oil and gas industry and is more significant in aged pipeline (Netto et al., 2005). The practical techniques of identifying rate of corrosion in oil and gas pipeline are the use of highresolution magnetic flux leakage (MFL) or ultrasonic technology (UT) tools (Ahammed, 1998; Mohitpour et al., 2007; Caleyo et al., 2002; EL-Abbasy et al., 2014). Furthermore, with all these procedures, there exist two challenges that include; the inability to estimate when an affected pipeline is expected to fail in service due to corrosion defect and understanding the physic/mechanism of corrosion growth rate as it affects the integrity of a pipeline. These challenges have generated different theories leading to various predictive approaches and models (Caleyo et al., 2002; Hallen et al., 2002). De Waard and Milliams (1975), study shown that rate of corrosion increases with $\mathrm{CO}_{2}$ 
partial pressure and temperature until it approaches a maximum value at temperature $60-70^{\circ} \mathrm{C}$ and then decreases until $90^{\circ} \mathrm{C}$. De Waard et al. (1995) developed a semi-empirical model with the application of data acquired from a high-pressure test facility. The model they proposed incorporate the contributions of kinetics of corrosion reaction and mass transfer of dissolved carbon dioxide. The model, however, fall to account for the oil composition. Jepson et al. (1996) came up with an empirical model for rate of corrosion prediction in horizontal multiphase slug flow pipelines. In their model relates the rate of corrosion to the pressure gradient across the mixing zone, temperature, $\mathrm{CO}_{2}$ partial pressure and water cut. In addition, the model has been enhanced in 1997 to further account for the effect of slug frequency and oil type (Jepson et al., 1997). Xiao et al. (2002) in their study a mechanistic model was proposed for $\mathrm{CO}_{2}$ corrosion in horizontal multiphase slug flow in 2002. The study covers the electrochemical reactions on steel surface, the chemistry of fluid, and mass transfer between the metal surface and the fluid. Nesic et al. (1995) in their investigation a comprehensive model was develop for internal corrosion prediction in mild steel pipelines. Several factors affecting the rate of corrosion include $\mathrm{H}_{2} \mathrm{~S}$, water entrainment in multiphase flow, corrosion inhibition by crude oil components and localized attack have been examine into account in the model.

However, the results of the respective internal corrosion predictive method may deviate from the realistic corrosion rates when the internal environmental parameters of the inspection segments are outside the scope of the prediction model. Hence, the objective of this study is to develop a twelveparameter prediction model for investigating the under-pipe corrosion deposit condition of localized carbon steel in acidic media.

\section{MATERIALS AND METHOD}

Model Formulation and Governing Equations: The modeling of under deposit corrosion in oil and gas pipeline prediction were developed following the iterative steps involved from the theoretical and experimental background/understanding physics/corrosion mechanism of the study. The developed model equation can be solve manually or with any spreadsheet package unlike the neural network model which can only be solved by programming software that support neural network tools. The performance of the proposed model was determined by running a repeated test with experimentally determined corrosion rates for the given conditions. The twelve listed factors represent the main operational parameters in the model are individually analyzed. In analyzing the rate of corrosion through an oil and gas pipeline, the following assumptions were adopted: (i.) $\mathrm{CO}_{2}$ is the corrosive species present in the fluid flow (oil and gas) industry (ii.) The $\mathrm{pH}$ of the system varies with dependent on temperature (iii.) Corrosion is localized over the target surface of the oil and gas pipeline (iv.) Fluid viscosity and density varies with temperature dependent (v.) Sand deposit production is not negligible

The proposed Model takes the form below as;

$$
\log (C R)=\beta[K \bar{P}+\alpha]+M
$$

Where; $\mathrm{CR}=$ corrosion rate in $[\mathrm{mm} /$ year $]$

$$
\bar{P}=\log (\text { inputs matrix })
$$

$$
\text { inputs matrix }=\left[\begin{array}{c}
L \\
D \\
A \\
T \\
P \\
V \\
P_{C O_{2}} \\
p H \\
C l \\
S F \\
\rho \\
\mu
\end{array}\right]
$$

The original governing equation of the developed model thus depends on $L=$ spool length [mm], $D=$ diameter of pipe [mm], $A=$ age of pipe [years], $T=$ Temperature of fluid $\left[{ }^{0} \mathrm{C}\right], P=$ Flow Pressure [bar], $V$ $=$ Flow velocity $[\mathrm{m} / \mathrm{s}], \mathrm{P}_{\mathrm{CO}_{2}}=$ Partial Pressure of $\mathrm{CO}_{2}$ [bar], $\mathrm{pH}=$ oil $\mathrm{pH}[-], \mathrm{Cl}=$ Chloride content [mg/kg], $\mathrm{SF}=$ Sand flow Deposit $[\mathrm{m} / \mathrm{s}], \rho=$ Oil Density $\left[\mathrm{Kg} / \mathrm{m}^{3}\right], \mu=$ Oil viscosity $[\mathrm{cP}]$.

$K, \alpha, \beta$ and $M$ are constants matrices given as follows;

$$
\begin{aligned}
& K=\left[\begin{array}{c}
K_{1,1} K_{1,2} K_{1,3} K_{1,4} K_{1,5} K_{1,6} K_{1,7} K_{1,8} K_{1,9} K_{1,10} K_{1,11} K_{1,12} \\
K_{2,1} K_{2,2} K_{2,3} K_{2,4} K_{2,5} K_{2,6} K_{2,7} K_{2,8} K_{2,9} K_{2,10} K_{2,11} K_{2,12}
\end{array}\right] \\
& \alpha=\left[\begin{array}{l}
\alpha \\
\alpha
\end{array}\right] \\
& \beta=\left[\beta_{11} \beta_{12}\right]
\end{aligned}
$$

The constant $K[-]$ is the input parameters exponent factors, $\alpha[-]$ is the correlation factors and $\beta[-]$ is the transformed parameter coefficients. $M$ is the error correction constant. This constant reduces the error in the calculation of the corrosion rate. $M$ is a matrix of a single constant defined as;

$$
M=[M]
$$


Table 1: Constants of the model

\begin{tabular}{lcccc}
\hline $\mathbf{S} / \mathbf{N}$ & $\boldsymbol{K}_{\mathbf{1}}$ & $\boldsymbol{K}_{\mathbf{2}}$ & $\boldsymbol{\alpha}$ & $\boldsymbol{\beta}_{\mathbf{1}}$ \\
\hline $\mathbf{1}$ & -0.0149 & -0.0016 & -1.6284 & 3.5677 \\
$\mathbf{2}$ & 0.0754 & 0.0075 & -1.2582 & 6.9925 \\
$\mathbf{3}$ & 0.0793 & 0.0145 & & \\
$\mathbf{4}$ & -1.0542 & -0.4340 & & \\
$\mathbf{5}$ & 0.0953 & 0.0458 & & \\
$\mathbf{6}$ & 0.1341 & 0.0160 & & \\
$\mathbf{7}$ & 0.0453 & 0.0126 & & \\
$\mathbf{8}$ & -0.0909 & 0.0569 & & \\
$\mathbf{9}$ & 0.5379 & 0.4765 & & \\
$\mathbf{1 0}$ & 0.0047 & 0.0060 & & \\
$\mathbf{1 1}$ & 0.8456 & 0.4839 & & \\
$\mathbf{1 2}$ & -0.6520 & -0.2381 & & \\
\hline
\end{tabular}

Table 2: Inputs Field Data

\begin{tabular}{|c|c|c|c|c|c|c|c|c|c|c|c|}
\hline $\begin{array}{l}\text { Pipe length } \\
\text { (mm) }\end{array}$ & $\begin{array}{l}\text { Diameter } \\
\text { (mm) }\end{array}$ & $\begin{array}{l}\text { Pipeage } \\
\text { (year) }\end{array}$ & $\begin{array}{l}\text { Fluid } \\
\text { temp } \\
\text { (oC) }\end{array}$ & $\begin{array}{l}\text { Pressure } \\
\text { (bar) }\end{array}$ & $\begin{array}{l}\text { Velocity } \\
(\mathrm{m} / \mathrm{s})\end{array}$ & $\begin{array}{l}\mathrm{CO}_{2} \text { partial } \\
\text { pressure } \\
\text { (bar) }\end{array}$ & $\mathrm{pH}$ & $\begin{array}{l}\text { Chloride } \\
\text { (mg/Kg) }\end{array}$ & $\begin{array}{l}\text { Sand } \\
\text { flow } \\
(\mathrm{m} / \mathrm{s})\end{array}$ & $\begin{array}{l}\text { Oil } \\
\text { density }\end{array}$ & $\begin{array}{l}\text { Oil } \\
\text { viscosity }\end{array}$ \\
\hline $\begin{array}{l}211 \\
45\end{array}$ & $\begin{array}{l}304.8 \\
508\end{array}$ & $\begin{array}{l}6 \\
37\end{array}$ & $\begin{array}{l}44 \\
67\end{array}$ & $\begin{array}{l}55 \\
70\end{array}$ & $\begin{array}{l}2.7 \\
1.2\end{array}$ & $\begin{array}{l}4.5 \\
2.5\end{array}$ & $\begin{array}{l}5.6 \\
3.9\end{array}$ & $\begin{array}{l}34.6 \\
36.5\end{array}$ & $\begin{array}{l}1.67 \\
1.04\end{array}$ & $\begin{array}{l}832.60 \\
818.80\end{array}$ & $\begin{array}{l}24.81 \\
10.73\end{array}$ \\
\hline 121 & 609.6 & 19 & 69 & 52 & 1.02 & 3.8 & 3.5 & 35.9 & 0.98 & 817.54 & 10.00 \\
\hline 300 & 400 & 16 & 35 & 64 & 1.81 & 6.0 & 6.4 & 30.7 & 0.92 & 838.18 & 37.18 \\
\hline 700 & 610 & 29 & 70 & 36 & 1.01 & 4.6 & 5.2 & 36.1 & 0.58 & 816.88 & 9.65 \\
\hline 500 & 600 & 32 & 69 & 62.8 & 0.92 & 5.4 & 3.8 & 353 & 0.45 & 817.59 & 10.03 \\
\hline 60 & 609 & 25 & 55 & 70 & 0.82 & 2.2 & 5.6 & 34.7 & 0.43 & 825.98 & 16.28 \\
\hline 500 & 192.7 & 8 & 35 & 39 & 2.85 & 2.2 & 5.8 & 32.9 & 1.83 & 838.07 & 36.95 \\
\hline 242 & 406.4 & 26 & 67 & 56 & 1.85 & 5.8 & 3.4 & 37.1 & 0.98 & 818.74 & 10.70 \\
\hline 119 & 914 & 28 & 45.5 & 59 & 0.98 & 4.9 & 5.1 & 34.8 & 0.67 & 831.69 & 23.36 \\
\hline 55 & 305 & 40 & 70 & 60 & 2.71 & 5.3 & 6.4 & 35.2 & 2.01 & 816.98 & 9.70 \\
\hline 100 & 508 & 30 & 48 & 64 & 1.56 & 2.5 & 4.3 & 36.9 & 1.02 & 830.19 & 21.17 \\
\hline 1000 & 225 & 13 & 55 & 40 & 2.2 & 2.0 & 5.24 & 33.8 & 1.97 & 825.85 & 16.17 \\
\hline 45 & 508 & 41 & 67 & 30 & 1.95 & 3.4 & 5.86 & 37.9 & 1.04 & 818.63 & 10.63 \\
\hline 60 & 609 & 15 & 53 & 45 & 1.08 & 2.9 & 5.34 & 34.3 & 0.69 & 827.08 & 17.42 \\
\hline 500 & 192.7 & 11 & 45 & 37 & 2.92 & 2.2 & 5.23 & 31.7 & 1.56 & 831.91 & 23.71 \\
\hline 121 & 609.6 & 6 & 70 & 67 & 0.76 & 2.6 & 3.6 & 38.7 & 0.41 & 817.01 & 9.71 \\
\hline 211 & 304.8 & 31 & 45 & 45 & 2.62 & 5.4 & 5.7 & 34.5 & 1.78 & 831.94 & 23.76 \\
\hline 210 & 304.8 & 27 & 66.5 & 69 & 1.75 & 4.3 & 5.45 & 34.7 & 1.08 & 819.09 & 10.91 \\
\hline 250 & 406.4 & 8 & 63 & 49.5 & 2.85 & 3.4 & 5.67 & 30.1 & 1.12 & 821.09 & 12.22 \\
\hline
\end{tabular}

\section{RESULTS AND DISSUSION}

Using data from a particular field $\mathrm{Z}$ in the Niger Delta region of Nigeria for twenty different cases to first validate the proposed model for uniform/localized corrosion, the results gotten from both field and the one predicted by the proposed model are as shown in Table 3.

Table 3: Comparison of Field, DeWaard and ANN with the proposed model

\begin{tabular}{llllll}
\multicolumn{5}{c}{ Table 3: Comparison of Field, DeWaard and ANN with the proposed model } \\
\hline Pipeline & $\begin{array}{l}\text { Field value } \\
\text { CR[mm/yr] }\end{array}$ & $\begin{array}{l}\text { DeWaard Lotz } \\
\text { CR[mm/yr] }\end{array}$ & $\begin{array}{l}\text { DeWaard Milliams } \\
\text { CR[mm/yr] }\end{array}$ & $\begin{array}{l}\text { AAN Model } \\
\text { CR[mm/yr] }\end{array}$ & $\begin{array}{l}\text { This Study } \\
\text { CR[mm/yr] }\end{array}$ \\
\hline 1 & 0.020 & 0.060 & 0.068 & 0.030 & 0.038 \\
2 & 0.141 & 0.012 & 0.106 & 0.190 & 0.115 \\
3 & 0.035 & 0.014 & 0.151 & 0.040 & 0.071 \\
4 & 0.028 & 0.047 & 0.057 & 0.030 & 0.028 \\
5 & 0.060 & 0.017 & 0.177 & 0.060 & 0.065 \\
6 & 0.134 & 0.018 & 0.191 & 0.140 & 0.080 \\
7 & 0.025 & 0.007 & 0.064 & 0.030 & 0.045 \\
8 & 0.022 & 0.043 & 0.029 & 0.020 & 0.018 \\
9 & 0.123 & 0.047 & 0.187 & 0.110 & 0.125 \\
10 & 0.046 & 0.013 & 0.076 & 0.050 & 0.058 \\
11 & 0.216 & 0.072 & 0.195 & 0.210 & 0.171 \\
12 & 0.062 & 0.015 & 0.054 & 0.070 & 0.082 \\
13 & 0.031 & 0.029 & 0.06 & 0.030 & 0.025 \\
14 & 0.143 & 0.024 & 0.131 & 0.150 & 0.127 \\
15 & 0.045 & 0.011 & 0.072 & 0.030 & 0.033 \\
16 & 0.026 & 0.045 & 0.044 & 0.030 & 0.017 \\
17 & 0.054 & 0.008 & 0.121 & 0.060 & 0.059 \\
18 & 0.035 & 0.070 & 0.080 & 0.030 & 0.064 \\
19 & 0.136 & 0.042 & 0.151 & 0.140 & 0.086 \\
20 & 0.044 & 0.039 & 0.114 & 0.050 & 0.026 \\
\hline
\end{tabular}


From the validation set of the proposed model shown in table 3, the error resulting is analyzed using Root mean square error (RMSE), Mean absolute error (MAE), Scattered index (SI) and Coefficient of determination $\left(\mathrm{R}^{2}\right)$ parameters. Fig 1 depicts the variation of this proposed model and the field data. Having compared the propose and other models, other commonly used empirical correlations are also compared with the developed model in order to check its performance as shown in Table 4.

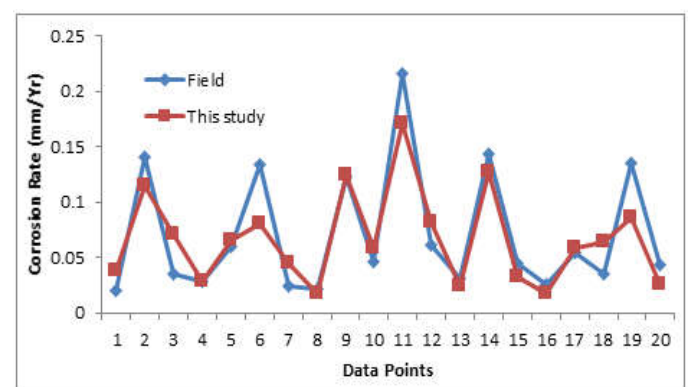

Fig 1: Variation of Proposed Model and Field Data

Table 4: Comparison of Proposed model with other empirical models

\begin{tabular}{lllll}
\hline Measurement & WAARD LOTZ & WAARD MILLIAM & ANN MODEL & This study (Model) \\
\hline RMSE & 0.068 & 0.052 & 0.012 & 0.024 \\
MAE & 0.053 & 0.042 & 0.007 & 0.019 \\
SI & 2.160 & 0.495 & 0.170 & 0.371 \\
$\mathrm{R}^{2}$ & 0.023 & 0.533 & 0.956 & 0.824 \\
\hline
\end{tabular}

The developed model equation can be solve manually or with any spreadsheet package unlike the neural network model which can only be solved by programming software that support neural network tools. The performance of the developed model was determined by running a repeated test with experimentally determined corrosion rates for the given conditions. The table 4 shows that neural network performed best with minimum errors and scatter index. The proposed model performed better than the rest apart from neural network model, but the rational here the proposed model can be computed manually or with any spreadsheet with easy, without undergoing the constrain of training and re-training, testing and validation regression plots. The figure 2 is the plots of predicted corrosion rate result versus field results for the model.
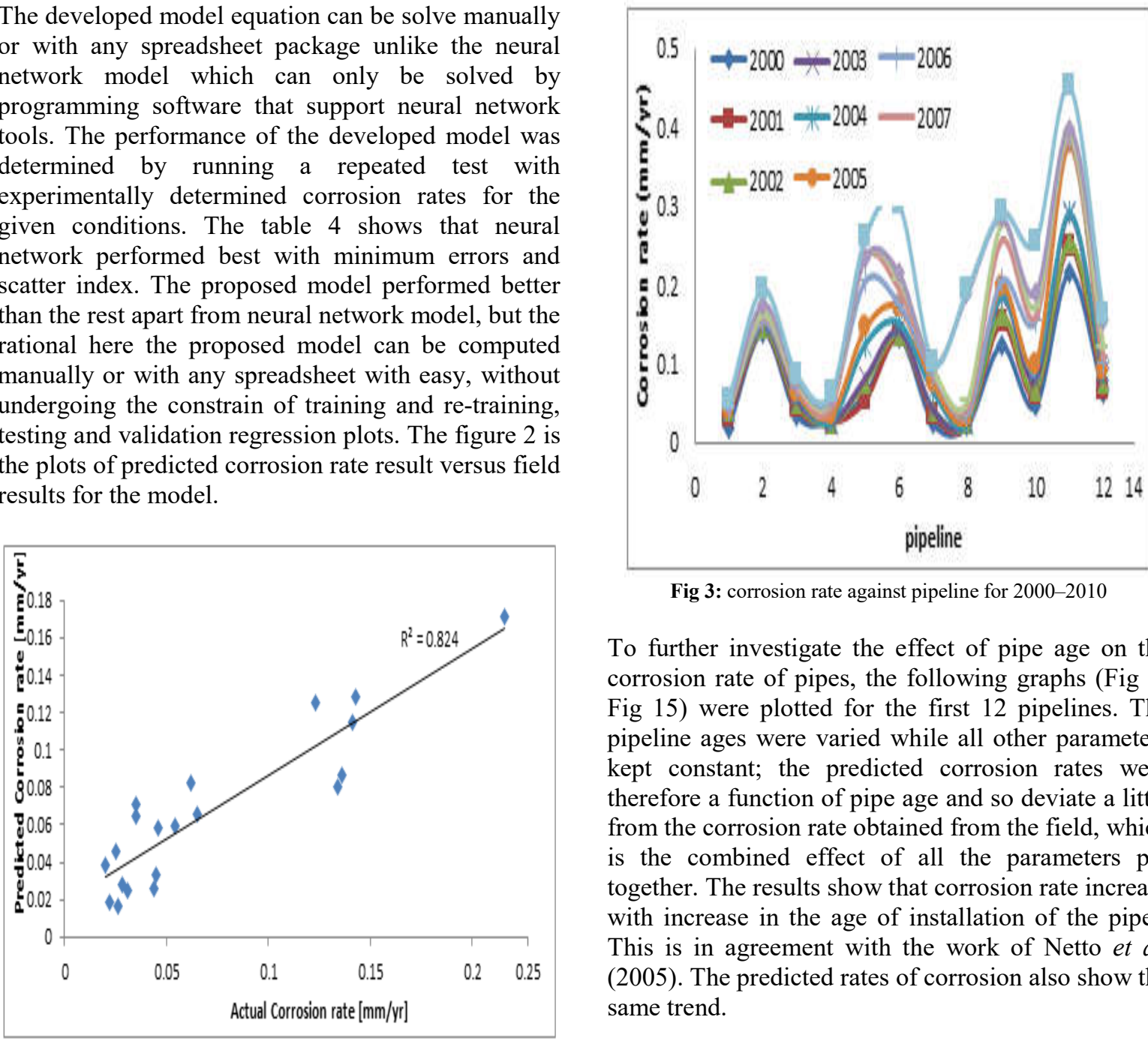

Fig 3: corrosion rate against pipeline for 2000-2010

To further investigate the effect of pipe age on the corrosion rate of pipes, the following graphs (Fig 3Fig 15) were plotted for the first 12 pipelines. The pipeline ages were varied while all other parameters kept constant; the predicted corrosion rates were therefore a function of pipe age and so deviate a little from the corrosion rate obtained from the field, which is the combined effect of all the parameters put together. The results show that corrosion rate increase with increase in the age of installation of the pipes. This is in agreement with the work of Netto et al. (2005). The predicted rates of corrosion also show the same trend.

Fig 2: Proposed Model Performance plot 


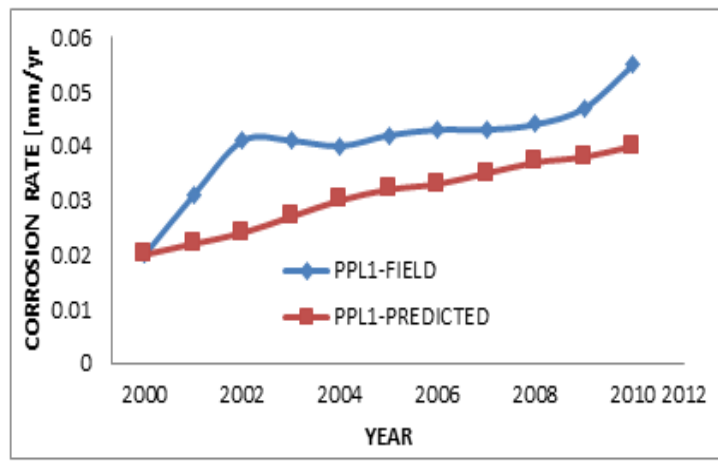

Fig 4: corrosion rate against time for pipeline 1

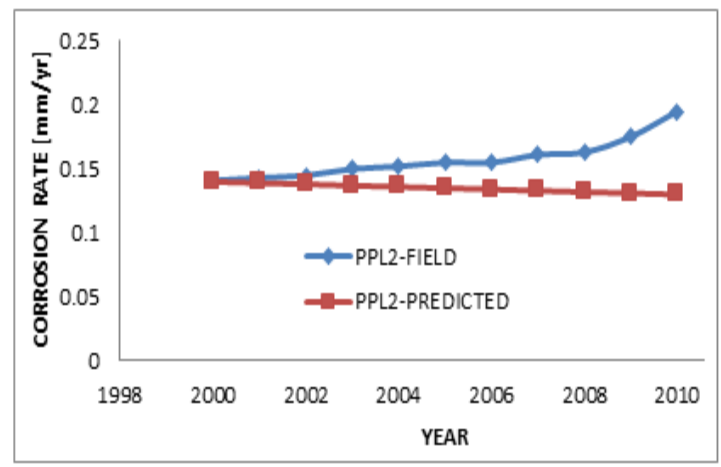

Fig 5: corrosion rate against time for pipeline 2

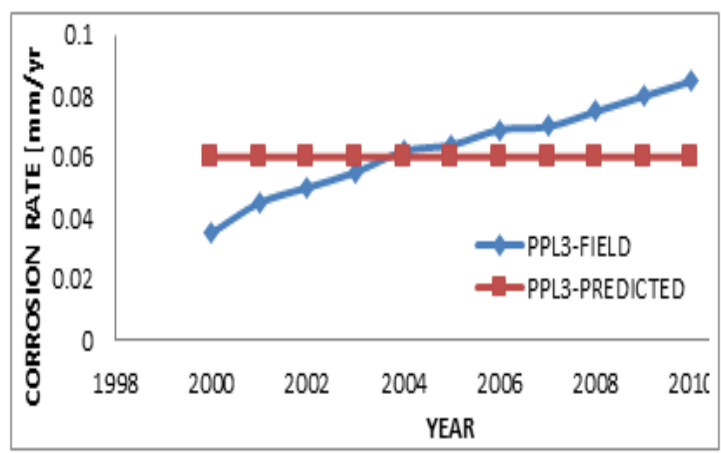

Fig 6: corrosion rate against time for pipeline 3

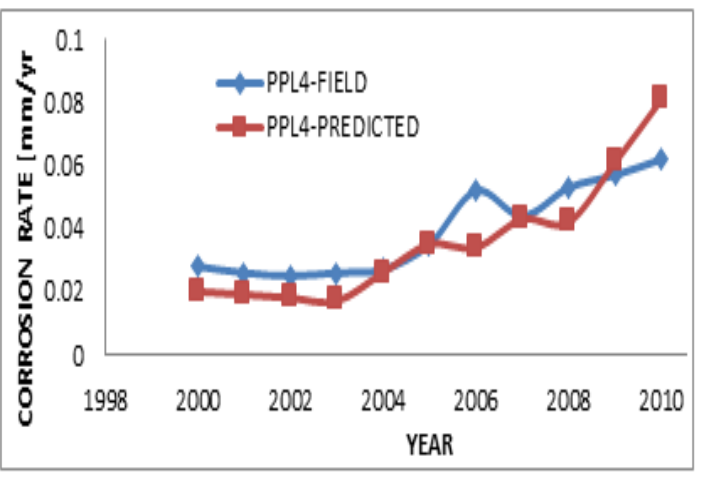

Fig 7: corrosion rate against time for pipeline 4

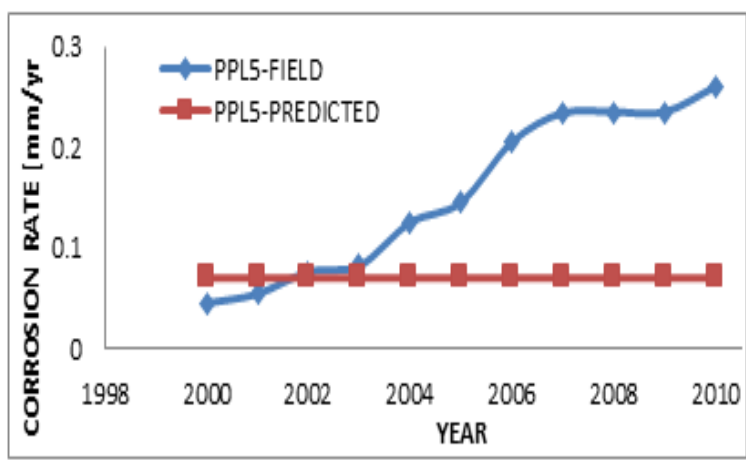

Fig 8: corrosion rate against time for pipeline 5

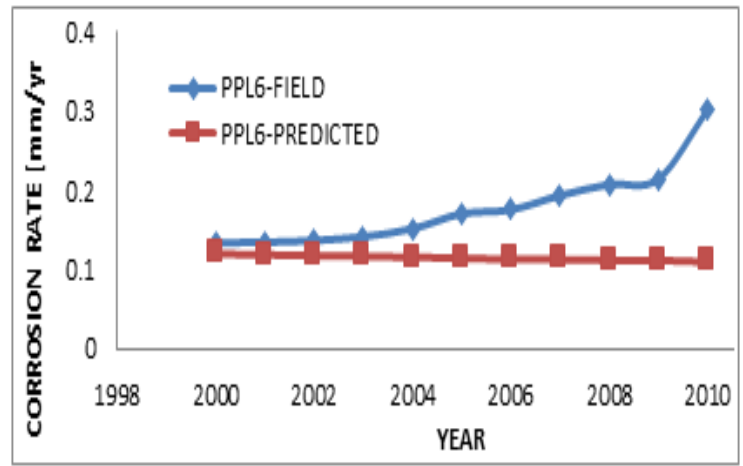

Fig 9: corrosion rate against time for pipeline 6

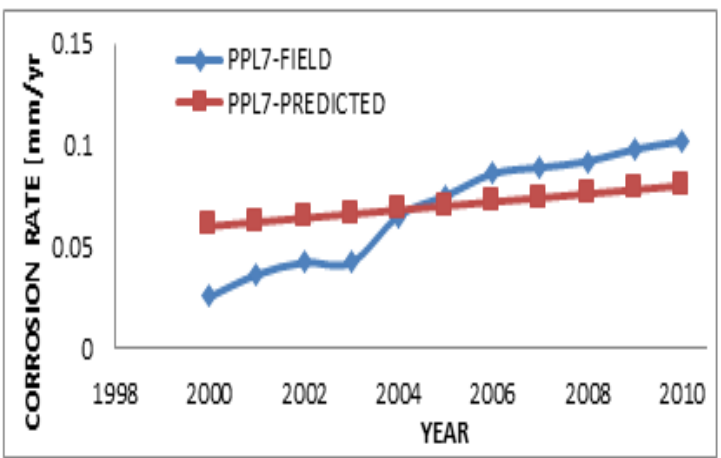

Fig 10: corrosion rate against time for pipeline 7

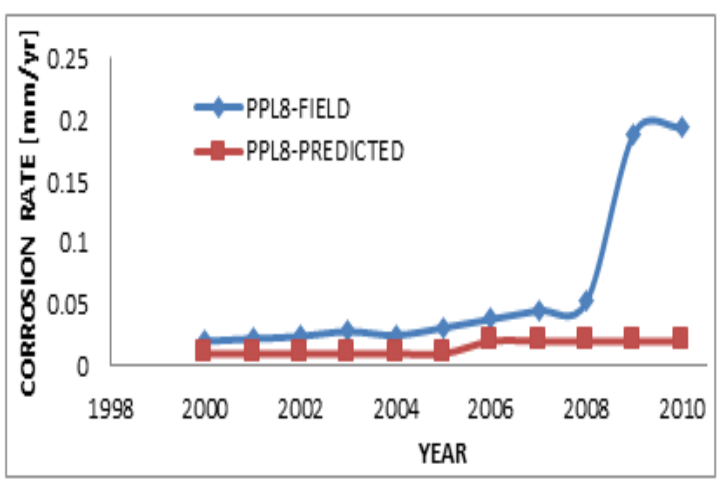

Fig 11: corrosion rate against time for pipeline 8 


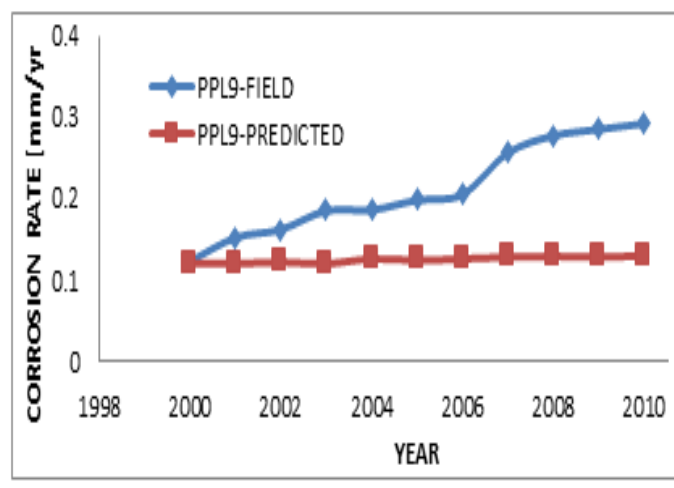

Fig 12: corrosion rate against time for pipeline 9

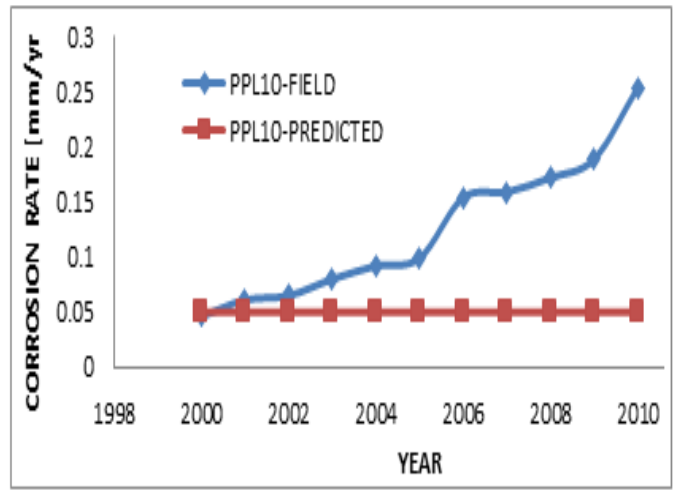

Fig 13: corrosion rate against time for pipeline 10

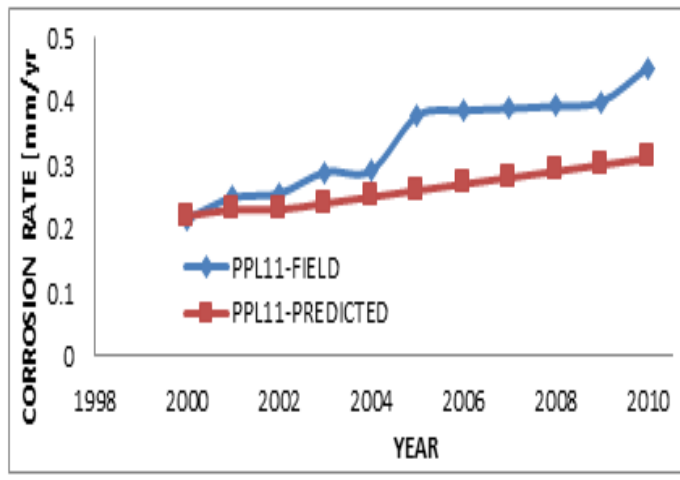

Fig 14: corrosion rate against time for pipeline 11

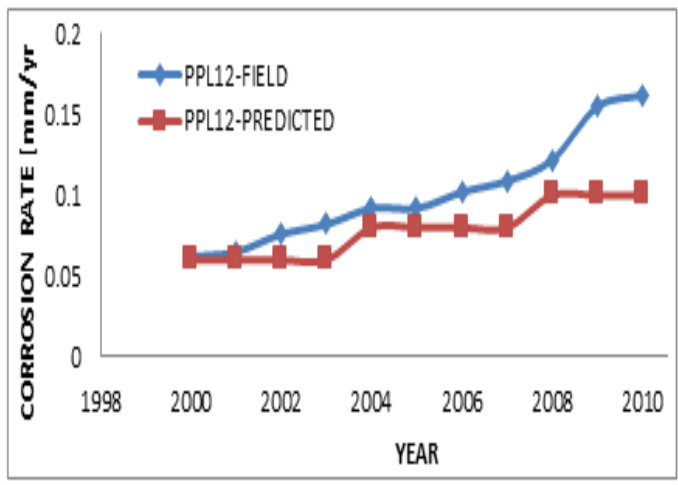

Fig 15: corrosion rate against time for pipeline 12
Conclusion: This study presents development of twelve-parameter prediction model for examining the under-pipe corrosion deposit condition of localized carbon steel in acidic media. The proposed analytical model was tested against De Waard Lotz, Milliams models and experimental result and found to give reasonably accurate results. The intention of this paper is to present a method that can be used to easily introduce complex nonlinear condition in relevant undergraduate/postgraduate engineering with manual computation coupled with less error and very simple method in application for better corrosion management.

\section{REFERENCE}

Ahammed, M (1998). Probabilities Estimation of Remaining Life of a Pipeline in the Presence of Active Corrosion Effects. Int. J. Press. V. and Pip/, Elvier. (75): 321-329.

Caleyo, F; Gonzalez, JL; Hallen, JM (2002). A study on the reliability assessment methodology for pipelines with active corrosion defects. Int. J. of Press. V. and Pip. Elvier. 79(1): 77-86.

DeWaard, C and Milliams, DE (1975). Carbonic acid corrosion of steel. Corr. 31(5): 177-181.

DeWaard, C; Lotz, U; Dugstad, D (1995). Influence of liquid flow velocity on $\mathrm{CO}_{2}$ corrosion: A semiempirical model. Corrosion/95, Paper No. 128, Houston, TX: NACE Inter.

EL-Abbasy, MS; Senouci, A; Zayed, T; Mirahadi, F; Parvizedghy, I (2014a). An artificial neural network Model for predicting condition of Offshore Oil and Gas pipelines. Autom. in constr. El.vier. 45: 50-65.

Hallen, JM; Gonzalez, JL; Caleyo, F; Lagos, FF (2002). In-line Inspection Guides Integrity Assessment of Sour Gas. Oil and Gas J. 62-68.

Jepson, WP; Bhongale, S; Gopal, M (1996). Predictive model for sweet corrosion in horizontal multiphase slug flow. NACE Inter. Conf. Series, Corrosion/96: Paper 19

Jepson, WP; Stitzel, S; Kang, C; Gopal, M (1997). Model for sweet corrosion in horizontal multiphase slug flow. Corrosion/97, Paper No. 602 , NACE Inter.

Mohitpour, H; Goshen, A; Murray (2007). Pipeline Design and Construction: A Practical Approach Third Edition 
Nesic, S.; Postlethwaithe, J; Olsen, S (1995). An electrochemical model for the prediction of $\mathrm{CO}_{2}$ corrosion. Corrosion/95, Paper No. 131, NACE Inter.

Netto, TAUS; Ferraz, SF; Estefen, (2005). The Effect of Corrosion defects on the Burst Pressure of Pipelines. J. of Constr. Steel Research, Elvier. 61(5):1185-1204.

Revie, W and Uhlig, H (2008). Corrosion and Corrosion Control: An Introduction to Corrosion Science and Engineering, Fourth Edition. A John Wiley and Sons, Inc, Publ. NJ. 513-514.
Tawancy, HM; Al-Hadhrami, LM; Al-Yousef, FK (2013). Analysis Corroded Elbow Section of Carbon Steel Piping System of Oil-Gas Separator Vessel. C. S. in Engg. Fail. Analy. 1(1):6-14.

Teixeira, AP; Netto, TA; Guiedes, CS; Estefen, ST (2008). Reliability of Pipelines with Corrosion defects. Int. J. of Press. Vesss. and Piping Elsvier. 85(4): 228-237.

Xiao YD; Liang CF; Zheng QF; Hu XJ; Wang L; Zhang EP (2002). "Nine five" data collection of atmospheric corrosion of materials. The Major Program of the National Natural Science Foundation of China (No. 59899141). 